\title{
FEMIGRAMA: POESÍA CON VOZ DE MUJER
}

FEMIGRAM: POETRY WITH FEMALE VOICE

José Cenizo Jiménez

Universidad de Sevilla

\section{Resumen:}

Este artículo anuncia la publicación de una antología de poemas de treinta mujeres poetas, así como sus temas principales y la justificación de la misma. La antología incluye la poética de las autoras y una biobibligrafía.

\section{Palabras clave:}

antología poética, mujeres, publicación

\section{Abstract:}

This article announces the publication of an anthology of poems by thirty women poets, as well as their main themes and the justification for it. The anthology includes the poetics of the authors and a bio-literature.

\section{KeYWORDS:}

poetic antology, women, publication 
Una excelente idea editorial ha llegado a las manos de los lectores. Una antología de poemas de treinta mujeres poetas (poetisas no acaba de gustarnos). La coordinadora de la misma, María Jesús Soler Arteaga, profesora y ella misma poeta, explica en la introducción la intención, "ser muestra de algunas de las voces más interesantes y representativas en la poesía actual escrita por mujeres, así como un recuerdo, una memoria fértil, de los versos que nos compartieron". Se refiere a mujeres en un ámbito concreto, de todas formas, por más que algunas, como María Sanz, sin duda la mejor y más conocida, al menos por nosotros, sean referencia más allá del panorama andaluz. De hecho, las antologazas participaron en un ciclo de recitales en bibliotecas municipales andaluzas.

Recuerda la coordinadora que en el siglo XIX se produjo la incorporación de la mujer al panorama literario y defiende la necesidad de antologías femeninas. Pero en el debate de si hay una escritura propiamente femenina cree que lo importante en la literatura no es la voz sino las palabras. Estamos de acuerdo, claro está.

De entre las seleccionadas hay algunas que han adquirido cierto renombre, como María Sanz o Rocío Arana, y tienen edades muy variadas -alguna nació a finales de los cincuenta, pero la mayor parte son mucho más jóvenes-. Por fuerza, la calidad, aceptable en general, es igualmente diversa, así como los temas, estilos, estrofas, etc. Hallaremos décimas, algún soneto, mucho verso libre e incluso su porción -ya inevitable, al parecer- de poesía visual o algo así (hasta un interesante acróstico interno de Siracusa Bravo que, señalando letras en negrita, se puede leer amor-odio). Se acompaña a cada selección una biobibliografía y una poética personal.

Por estas páginas pasan todos los temas que preocupan a las mujeres (y a los hombres, claro). El amor, como en Rocío Hernández ("Dime que no, que habremos de evitarlo; / es la historia más triste que conozco. / Dime que nuestro amor es un prodigio / pagano, arrebatado, irrepetible", p. 86) o Esperanza López ("En tus labios, puerto abrigado, / van a atracar mis besos y echarán / anclas enamoradas en tan cálido/ fondeadero", p. 110). Hermosos versos, y también los de desencuentro amoroso en Rosario Pérez. Como los que se centran en la memoria, de Alicia Jurado: "No perder la cordura, / el norte de los sueños, / lo que sí existió / aunque ya es ido. / Dejar que la memoria / haga bien su trabajo. / Y que de vez en cuando / aneguen los recuerdos/ los diques del olvido" (p. 98). O los que reflexionan sobre el paso del tiempo, de la premiadísima y poderosa María Sanz: “(...) / Y lo entiendes mejor. Sabes que el tiempo/ acabará con toda pertenencia, / con todo lo que aún no se posee, / y hasta con esas luces que te inundan / de su clara verdad (...) (p. 218)". Y los efectos intertextuales e interculturales de María Jesús Soler Arteaga, la simbología del mar "ante lo imposible bello" de Ana Rodríguez, el acierto expresivo de Carmen Moral, etc. En definitiva, una 
buena selección, rica y necesaria, para conocer mejor a las mujeres que nos alumbran, hoy, con su poesía. 